\title{
El pensamiento especulativo en clave contemporánea: Hegel $y$ la filosofía de la diferencia
}

\author{
Speculative Thought from a Contemporary Perspective: \\ Hegel and Difference Philosophy
}

MARÍA LUCIANA CADAHIA*

\begin{abstract}
Resumen: En este artículo elaboraremos un examen riguroso sobre el supuesto antagonismo entre la llamada filosofía de la identidad (Hegel) y la filosofía de la diferencia. El interrogante que estará a la base de todo nuestro escrito será el siguiente: si definimos la estrategia del pensamiento de la diferencia como el intento de distinguir a un elemento de sí mismo y hacerlo devenir en un proceso de diferenciación, ¿este movimiento no tiene grandes afinidades con la lógica especulativa, puesto que la noción reflexiva de diferencia que plantea Hegel posibilita una salida de la identidad criticada por el pensamiento de la diferencia?

Palabras claves: diferencia; identidad; especulación; dialéctica.
\end{abstract}

\begin{abstract}
This article elaborates an examination of the alleged antagonism between the so-called political philosophy of identity (Hegel) and the political philosophy of the difference (Deleuze and Derrida). That is the interrogation at the base of this text: if we define the strategy of difference thought as an attempt to distinguish an element from itself and, instead of safekeeping its identity, we make it become a process of differentiation, wouldn't this movement have strong affinities with speculative logic, in the sense that reflexive notion of difference proposed by Hegel already implies an alternative to identitarian logic, so criticized by difference thought?
\end{abstract}

Keywords: difference; identity; speculation; dialectics.

I.

A partir de cierta recepción del pensamiento de Heidegger y Lévinas se fue consolidando una filosofía de la diferencia ontológica, entendida como el intento de pensar lo otro como otro, es decir, como una exterioridad irreductible a lo uno ${ }^{1}$. Podría decirse que pensar la diferencia en sí misma, esto es, lo diferente desde lo diferente, sin pasar por la representación y lo negativo, parecía haberse convertido en el horizonte de sentido ineludible para la práctica de la filosofía

Fecha de recepción: 04/02/2013. Fecha de aceptación: 26/04/2013.

* Doctora en Filosofía por la Universidad Autónoma de Madrid. Profesora Titular y Coordinadora de la Maestría en Sociología del Departamento de Sociología y Estudios de Género de la Facultad Latinoamericana de Ciencias Sociales (FLACSO, sede Quito).Contacto: luciana.cadahia@gmail.com

1 Cf. A. Crockett y C. Davis, «Risking Hegel: A New Reading», en: S. Žižek, C. Crockett y C. Davis (eds.): Hegel and the Infinite. Religión, Politics and Dialectic, New York, Columbia University Press, 2011, pp. 1-17. 
francesa de finales de los años 60. En muchos casos, casi siempre por una sucesión de malentendidos, esta exploración de la diferencia fue comprendida como el imperativo de distanciarse de Hegel. No hace falta más que recordar la apreciación de Lévinas sobre el pensamiento de Hegel como ejemplo paradigmático del pensador totalizante que crea un mundo en el cual todas las cosas y formas de otredad son absorbidas por la lógica de la identidad, a causa de la violencia totalizadora ejercida por el método hegeliano y su respectiva ontología idealizada ${ }^{2}$. Bien es cierto, pues, que había una guerra declarada contra cierto hegelianismo, no obstante, las relaciones del pensamiento de la diferencia con Hegel siempre han sido más difíciles de precisar. Al fin y al cabo, renunciar al pensamiento especulativo mediante el recurso de una tensión dialéctica con Hegel nos parecería apenas una curiosa ironía histórica si no estuviera en juego nuestra posibilidad de elaborar un pensamiento político acorde con los problemas de hoy. En la actualidad, nos encontramos ante una decisión difícil, a saber, cómo pronunciarnos al respecto. Surge así la necesidad de una elección, de saber que la posibilidad y la obligación de elegir nos interpela de modo acuciante. Entre las distintas elecciones, hay una que parece más inminente: cómo vamos a vincularnos con nuestro propio legado filosófico. Por eso, frente a la opinión de quienes creen que el pensamiento de la diferencia -sobre todo la línea francesa- habría puesto fin a una etapa del pensamiento occidental -es decir, el pensamiento de la identidad-, nos parece más conveniente volver a preguntarnos por esta voluntad de superación.

Es necesario indagar sobre el sentido de esta elección, sobre todo en las propuestas filosóficas de Jacques Derrida y Gilles Deleuze, dado que no sólo hicieron explícita su distancia con Hegel, sino que para ello partieron de las premisas del pensamiento de Heidegger y Lévinas. En esta dirección, quizá sea más acertado considerar el vínculo con Hegel no tanto en los términos de una superación inaplazable, sino más bien como el lugar de trabajo e indagación de un problema. Seguir defendiendo la idea de la superación no hace más que perpetuar la esterilidad propiciada por las lecturas parciales de Hegel-cuyas consecuencias más alarmantes serían la simplificación de la dialéctica y una condena del pensamiento especulativo como mera ambición totalizante-. Con todo, si bien es cierto que los denominados «pensadores de la diferencia» contribuyeron a crear la ficción de que el ingreso en la nueva era de la filosofía pasaba por superar a Hegel, fueron esos mismos filósofos los que rápidamente reconocieron las dificultades de semejante empresa. Por su parte, Derrida llegó a afirmar que «nunca terminamos de leer o releer a Hegel y, en cierto sentido, yo no hice más que intentar explicarme a mí mismo sobre este punto» ${ }^{3}$. Y Deleuze, casi siempre tan hábil para colonizar cuerpos filosóficos en los que acaba engendrando felices monstruosidades ${ }^{4}$, misteriosamente nunca consiguió parasitar el pensamiento especulativo ${ }^{5}$. Probablemente esta experiencia límite y refractaria

2 La imagen que Lévinas construye de Hegel repite sin saberlo el núcleo del pensamiento hegeliano, puesto que reduce éste a una entidad simple (an sich.) Ejerce tal violencia sobre él que convierte su filosofía en una identidad solidificada. Es como si el movimiento lógico (o más bien su falta) del pensamiento de Lévinas asumiese la forma misma de aquello que él acusa. Véase E. Lévinas, Totalidad e infinito. Salamanca, Sígueme, 1977.

3 J. Derrida, Positions, Minuit, Paris 1972, pp. 103-104.

4 Para tener una idea más precisa del proceder deleuziano con los filósofos modernos véase A. Toscano, Theatre of Production: Philosophy and Individuation between Kant and Deleuze, Basingstoke, Palgrave, 2006.

5 Véase S. Žižek, Órganos sin cuerpo. Sobre Deleuze y consecuencias, Valencia, Pre-textos, 2006; también véase C. Crockett y C. Davis, op. cit., pp. 1-18. La tesis que comparten ambos textos es que las dificultades de Deleuze para enfrentarse a Hegel se deben precisamente a su cercanía con él. 
para con el pensamiento de Hegel, esta pretendida necesidad de ruptura con sus presupuestos básicos, constituya un primer modo de restablecer otro tipo de relación con él.

Para comprender el sentido del distanciamiento que han intentado llevar a cabo estos filósofos franceses hace falta adentrarse en la lógica especulativa, puesto que la Lógica, lugar en el que se encuentran las nociones de identidad y diferencia, lejos de ser un principio formal y vacío, «es un tejido móvil y vivo, el flujo de una melodía armónicamente escandida» ${ }^{6}$. Y ello, sobre todo, si tenemos en cuenta que las nociones de identidad y diferencia, en tanto determinaciones de reflexión en la lógica de la esencia, desembocan en el fundamento/fondo (Grund), siendo éste, el fundamento, la unidad de la identidad y lo diferente ${ }^{7}$. Solamente teniendo en cuenta el movimiento especulativo del pensamiento hegeliano es como podremos comprender el alcance y sentido de la estrategia elaborada por los filósofos franceses en sus pretensiones de superar a Hegel.

Como es sabido, la Ciencia de la Lógica está dividida en la Doctrina del ser, la Doctrina de la esencia (ambas comprendidas en la lógica objetiva) y la Doctrina del concepto (lógica subjetiva). El paso de la Doctrina del ser a la Doctrina de la esencia tiene lugar porque «la verdad del ser es la esencia», puesto que el ser, «por su naturaleza, se interioriza [recuerda], y por ese ir hacia dentro de sí viene a ser la esencia ${ }^{8}$. La esencia, entonces, está entre el ser (Doctrina del ser) y el concepto (Doctrina del concepto) y, al constituir el término medio entre éstos, su movimiento constituye la transición del ser al concepto y, al mismo tiempo, la reincidencia del concepto sobre el ser. Pero, a su vez, la esencia da razón de la esfera del ser en las determinaciones de reflexión» ${ }^{9}$. De este modo: «cada determinación de reflexión o esencialidad aparece así como criterio último de identificación, distinción o fundamentación de cuanto es» ${ }^{10}$. Como afirma Hegel en la Introducción de la Lógica: «La reflexión va más allá de lo concreto inmediato y, determinándolo, lo disgrega». Sin embargo, «en la misma medida, la reflexión tiene que ir más allá de esas sus determinaciones disgregadoras y hacer, por lo pronto, que éstas entren en referencia, puesto que: «Sobre la base de esta referencialidad sale a escena el antagonismo de las determinaciones (...) y la comprensión de su antagonismo es el gran paso negativo hacia el verdadero concepto de razón», a la vez que es «el acto por el cual se eleva la razón por encima de las limitaciones del entendimiento, y por el cual se disuelven esas limitaciones ${ }^{11}$. Así, la esencia, en tanto que disgregada en momentos, parece (scheint) como determinaciones reflexionadas dentro de sí. Primero, como identidad, es decir, como simple referencia a sí misma, puesta (gesetzt) como algo inmediato; luego, como determinación propiamente dicha, esto es, como diferencia, aunque primero como diversidad en

6 F. Duque, Historia de la Filosofía Moderna. La era de la crítica, Madrid, Akal, 1998, pág. 577.

7 Ya en el llamado «Fragmento de sistema» advertía Hegel de que el mero hablar de «la unión de la oposición y de la relación» podría «aislar a su vez esta unión, argumentando que se opone a la no-unión». La verdadera resolución de esa oposición no estaría, pues, en ver esa unión como «algo puesto, [...] algo del entendimiento, algo reflejado por la reflexión, sino que su único carácter para la reflexión consiste en que es un ser fuera de la reflexión.» (G. W. F. Hegel, Escritos de Juventud (=EJ), Madrid, FCE, 2003, pág.401).

8 G. W. F. Hegel, Wissenschaft der Logik $(=W d L)$. Erster Band. Die objektive Logik, en: F. Hogemann und W. Jaeschke (eds.), Gesammelte Werke, Band 11, Felix Meiner, Hamburg, 1978, 241. (Trad. esp.: F. Duque, Madrid, Abada, 2011, pág. 437).

9 WdL.G.W., 11: 243. (Trad., pág. 440).

10 F. Duque, op. cit., pág. 645.

11 WdL. G.W., 11: 17. (Trad., pág. 195). 
general y, luego, como oposición; y, finalmente, la esencia, en cuanto contradicción, reflexiona para sí y regresa a su fundamento ${ }^{12}$. Este regreso de la esencia al fundamento (Grund) debe ser entendido como la unidad de la identidad y lo diferente. Y cuando Hegel afirma esto no suprime las diferencias, sino que viene a decir que en «el principio de razón [o principio de fundamento]» «la verdadera esencialidad de algo no es su determinación como idéntico consigo, ni como distinto, ni como meramente positivo o como meramente negativo, sino que su verdadera esencialidad es que tiene su ser en otro» ${ }^{13}$. El fundamento, entonces, «es-la esencia-que-está-siendo dentro de sí y ésta es esencialmente fundamento, y fundamento lo es solamente en tanto es fundamento de algo, o sea, de un otro» ${ }^{14}$. Por tanto, lo relevante aquí no es ni la identidad en sí misma ni la diferencia en sí misma, sino el corte que hace a los extremos, en este caso como la relación (Verhältnis) identidad-diferencia, entendida como el movimiento de asumirse una determinación en otra, y de hundirse en el fundamento común que se despliega ontológicamente en ambos extremos. Por ello, la reflexividad de la mutua oposición (o sea, la contraposición o reflexión absoluta) no es la supresión de las diferencias, sino su asunción (Aufhebung), o sea el hacerse literalmente cargo cada uno de los extremos de la contradicción resultante de creerse con sentido por separado, o sea, y hablando con toda propiedad: de creerse absolutamente separado (no en vano se preguntó irónicamente Hegel en un opúsculo: ¿Quién piensa abstractamente?). Esto se comprende mejor si tenemos en cuenta los tres respectos de lo lógico: el abstracto -nivel del entendimiento-; el dialéctico (razón negativa); el especulativo (razón positiva) ${ }^{15}$. El primero se corresponde con la razón cuando ésta procede de manera abstracta, es decir, cuando se degrada ella misma a entendimiento y, al no reconocer el límite de éste, no consigue superar las contradicciones y sucumbe al «abismo de la nada, en el que se hunde todo ser». El segundo se corresponde con la razón negativa, que expone la limitación y unilateralidad de las determinaciones del entendimiento. Y, el tercero, es el respecto de la razón propiamente especulativa, la cual aprehende la unidad (¡no la identidad!) de las determinaciones en su oposición y disuelve la creencia en la existencia de «elementos dados» (propia del nivel del entendimiento) ${ }^{16}$ : «En este carácter dialéctico, tal como viene aquí tomado, y por ende en la captación de lo contrapuesto en su unidad o de lo positivo en lo negativo, consiste lo especulativo» ${ }^{17}$. De estos respectos va a partir Hegel para explicar por un lado, el carácter copulativo del ser, y, por otro, el Absoluto no ya como la «unidad resultante de la supresión de las diferencias (Aufgehobenseyn)», sino, como dice Duque: «la unidad de la diferencia y de la Aufhebung de la diferencia ${ }^{18}$. Por ello, la clave de comparación entre Hegel y el pensamiento francés contemporáneo no debe limitarse a las nociones de identidad y de diferencia, sino que debe atender al fundamento, o sea, a la superación especulativa de la unidad-contraposición entre diferencia e identidad. Así, vemos cómo a través del desarrollo del automovimiento interno de lo lógico, Hegel lleva a cabo una crítica a la concepción abstracta

12 Cf., WdL. G.W., 11: 258. (Trad., pág. 457).

13 G. W. F. Hegel, Enzyclopädie der philosophischen Wissenschaften im Grundrisse (1830) (= Enz.) en: W. Bonsiepen und H-C. Lucas (eds.), Gesammelte Werke, Band 20, Felix Meiner, Hamburg, 1992, § 121, Obs . (Trad. esp.: R. Valls Plana. Madrid, Alianza 1997, pág. 219).

14 Ibidem.

15 Cf. WdL. G.W., 11: 26-27. (Trad., pp. 204-205).

16 Cf. F. Duque, Historia de la Filosofía Moderna. La era de la crítica, op. cit., pág. 577.

17 WdL. G.W., 11: 27. (Trad., pág. 205).

18 F. Duque, op. cit., pág. 434 (nota a pie no 923 del libro).

Daimon. Revista Internacional de Filosofía, nº 64, 2015 
de la razón que -fijada como entendimiento- toma los elementos por separado. Precisamente por ello, Hegel hace de ese automovimiento el curso mismo de lo lógico: desde el ser hasta la idea. A este respecto, Hegel no dejará de insistir en la necesidad de que la filosofía debe elevarse al esfuerzo del concepto; y esto significa que debe comprehender el devenir-retorno inmanente de la idea a partir del ser y de la idea que vuelve a[l] ser.

Cuando Hegel comprende la esencia como pura negatividad autodeterminante del ser, puesto que: «El ser, en cuanto que él es no ser lo que él es, y ser lo que él no es, en cuanto esta simple negatividad de sí mismo, es la esencia» ${ }^{19}$, establece una ruptura fundamental con la clásica concepción de una infinitud positiva, inmediata y trascendente. Esto es así porque la esencia no es un paradigma inmóvil, sino el devenir a sí, relacional, de lo absoluto, el cual se niega en la inmanencia múltiple de lo existente, a la vez que reniega de ello. En virtud de esto, la contradicción que aparece en lo existente se realiza y se resuelve en lo que Hegel denomina «efectividad» ${ }^{20}$. Así como el devenir produce y resuelve la ínsita contradicción del ser, la efectividad produce y resuelve la contradicción de una esencia negada en su propia afirmación existencial, puesto que: «La realidad efectiva es la unidad devenida inmediata de la esencia y la existencia (Existenz), o de lo interior y lo exterior» ${ }^{21}$. Lo efectivo pone y supera la diferencia esencial, al modo de una relación o mediación absoluta que re-establece la unidad de lo existente sin eliminarlo. Si la esencia es para Hegel lo uno, lo es en el sentido de que constituye la reflexión de esta actualización, una «unidad consigo por medio de su ser otro». Aquí encontramos uno de los aspectos más originales del pensamiento hegeliano: se trata de un pensamiento que, en su exigencia conceptual, va más allá de la mera «identidad en la diferencia y la diferencia en la identidad ${ }^{22}$. Hegel expone así críticamente el concepto tradicional de la identidad al enfrentarlo a su propia contradicción, con lo cual la lógica especulativa es capaz de superar la reducción dualista del entendimiento representativo, más allá de la lógica formal de las oposiciones binarias, fijas e inamovibles, más allá del entendimiento abstracto, para el cual todo ser y toda diferencia representa una entidad estática, firme y positiva, relacionada de manera extrínseca con otras tantas entidades abstractas (positivas o negativas, que ello da igual), y disueltas finalmente en el proceso indefinido de lo que Hegel llamaba una mala infinitud. Por el contrario, de lo que se trata aquí, esencialmente, es del dinamismo diferencial inmanente de lo idéntico como «lo otro en sí mismo». Por eso, lo Lógico constituye la efectividad de su propio devenir, en los términos de una relación negativa consigo misma o diferenciación de sí. La identidad es en su diferencia, en su negatividad, en la alteridad que la confronta consigo misma. Por tanto, para Hegel, el fundamento de lo real (ipero es que el fundamento es lo verdaderamente «real»[das Reale]!) no reside en la simplicidad eterna e inmóvil del ser, sino que opera como des-fundamentación negativa de lo real. Por otra parte, aquello que el entendimiento pone de modo unilateral, fija e inmóvil, la razón dialéctica lo

19 WdL. G.W., 11: 232. (Trad., pág. 425).

20 Cf. WdL. G.W., 11: 380-381. (Trad., pp. 604-605).

21 Enz. § 142. G.W. 20: 164. (Trad., pág. 231).

22 Enz. § 118. G.W., 20:149. (Trad., pág. 216): «La igualdad es una identidad sólo de aquellos que no son los mismos, que son idénticos uno con otro; y la desigualdad es referencia de los desiguales. Ambas [igualdad y desigualdad] no caen en lados o aspectos distintos que sean exteriormente indiferentes uno a otro, sino que cada uno [de ellos] es un aparecer en el otro. La diversidad es, por consiguiente, distinción de la reflexión o distinción en sí misma, distinción determinada.» 
niega, invierte y abre, mientras que el pensamiento especulativo lo muestra en su unidad constitutiva. Lo que el Verstand separa y excluye, la Vernunft lo asume e incorpora concretamente. Aun cuando la identidad aparece como el punto de partida de las determinaciones de reflexión (y porque así aparece, o sea como algo inmediato y dado), al final se muestra retrospectivamente como despliegue inmanente de su propio proceso de diferenciación. De la igualdad que surge de la diferenciación también surge la verdad, pero no como una verdad que eliminara de sí la desigualdad: «a la manera como se elimina la escoria del metal puro, ni tampoco a la manera como se deja a un lado la herramienta después de modelar la vasija ya terminada, sino que la desigualdad sigue presente de un modo inmediato en lo verdadero como tal, como lo negativo, como el sí mismo» ${ }^{23}$. Un movimiento fundador y desfundador de lo finito, tal es la razón concreta que Hegel propone, puesto que «la autonegación de lo finito en su propia diferencialidad constituye la verdadera identidad, primero -en un nivel todavía formal-, de la esencia como principium essendi (el genuino «principio del ser»); después, en la cúspide del universal concreto como Idea» ${ }^{24}$. El no-ser de lo finito es el ser de lo absoluto, y de este modo lo infinito converge, por el principio de la inversión, con la negación de lo finito como superación de sí mismo. Porque en el origen no existe la identidad abstracta sino el movimiento de la escisión, el corte, la diferencialidad de los auto-diferentes, el ser de lo absoluto es, se da como el no ser de lo finito. O dicho en el lenguaje representativo: esto significa que Dios muere en el mundo a fin de que lo otro pueda ser (y en nuestro caso, saberse, sabernos), en cuanto «herido de muerte». La muerte-y-transfiguración de lo divino contiene toda «la seriedad, el dolor, la paciencia y el trabajo de lo negativo» ${ }^{25}$ como único medio de su propia (des)calificación ${ }^{26}$. Como sostiene igualmente Žižek: porque lo absoluto tiene el «coraje» y la «paciencia» de lo negativo, lo finito está signado por la muerte, pero por una muerte y una negatividad absolutamente superadas. El panlogismo de Hegel se niega sin embargo a detener la diferencia ínsita en todo lo finito. Y en eso radica su tragedia: en una repetición incansable que reinscribe por doquier el exceso de lo divino. Lo absoluto constituye el no-ser que divide y multiplica todas las cosas, las desfonda e invierte. El absoluto en Hegel «rompe claramente con la lógica metafísica del contar-para-Uno»; a la vez que impide cualquier exceso exterior al campo de las representaciones conceptuales. La totalización-en-Uno siempre fracasa, el Uno está siempre ya en una situación de exceso con respecto a sí mismo, es en sí mismo la subversión de lo que se propone conseguir; y es esta tensión interna del Uno, esta especie de devenir-más-de-uno en un sentido siempre cualitativo, que hace que lo Uno sea Uno y simultáneamente lo disloca, es esta tensión lo que constituye el movimiento del «proceso dialéctico».

En otras palabras, Hegel efectivamente niega que exista lo Real más allá de la red de representaciones conceptuales (razón por la cual se lo malinterpreta a menudo como un «idealista absoluto»), en el sentido del círculo cerrado de la totalidad del Concepto. Sin embargo, lo Real,

23 G. W. F. Hegel, Phänomenologie des Geistes (= Phä), en: W. Bonsiepen und R. Heede (eds.), Gesammelte Werke, Band 9, Felix Meiner Verlag, Hamburg, 1980, 30. (Trad. esp.: A. Roces, México, FCE, 2007, pág. 27).

24 F. Duque, op. cit., pág. 652.

25 Phä. G.W., 9: 18. (Trad., pág. 16): «La vida de Dios y el conocimiento divino pueden, pues, expresarse tal vez como un juego del amor consigo mismo; y esta idea desciende al plano de lo edificante e incluso de lo insulso si falta en ella la seriedad, el dolor, la paciencia y el trabajo de lo negativo.»

26 Cf. J. Hyppolite, Introduction à la philosophie de l'histoire de Hegel, París, Seuil, 1983, pág. 31; véase también J. Hyppolite, Logique et existence. Essai sur la logique de Hegel, Paris, Presses Universitaires de France, 1953, pág. 149. 
en el sentido en que lo interpretó Lacan, no desaparece aquí en el juego global y autorreferencial de la representaciones simbólicas; reaparece como una «venganza» (con especial atención al sentido de «devolución» que tiene el término revenge en inglés) en tanto agujero inmanente, en tanto obstáculo por cuya razón y «en base al fundamento (...) las representaciones nunca pueden totalizarse a sí mismas. Y por ello, dichas representaciones son (no-totales)» ${ }^{27}$. Precisamente porque para Hegel el centro está en todas partes, lo absoluto es también el medio (Mitte) y la unidad intrínseca de una relación infinita. La propuesta hegeliana propone así una constante diferenciación de lo mismo. La ruptura con la noción abstracta e inmediata de la identidad aportada por Hegel representa sin duda una significativa transformación en el modo de experimentar y concebir lo real. El pensamiento hegeliano ofrece, por tanto, una crítica capaz de superar el paradigma de la conciencia representativa y del sujeto inmediato y establece, desde un punto de vista lógico, las condiciones de inteligibilidad para el pensamiento político contemporáneo, toda vez que reemplaza el modelo dualista entendido como sujeto-objeto, deseo-deber, ser-pensamiento, infinitud-finitud, por una efectividad conceptual -reflexiva y diferencial- cuya totalidad se expresa en la actividad especulativa.

II.

Hasta el momento, pues, hemos considerado que la concepción hegeliana de lo absoluto no suprime las diferencias sino que es «la unidad de la diferencia y de la Aufhebung de la diferencia» ${ }^{28}$. Asimismo, esta afirmación descansa en una concepción cualitativa de la diferencia. Si la diferencia fuese cuantitativa, tal y como era considerada por la filosofía de la identidad anterior a Hegel, la oposición sería externa -dado que la cantidad es una determinación externa-. En cambio, en Hegel la diferencia entre los opuestos es interna y constitutiva de los mismos. La distinción que hace Hegel entre el infinito malo y la verdadera infinitud es clave para comprender este punto. Podríamos decir que el infinito malo es un círculo vicioso que descansa en la mera enunciación de una contradicción contenida en lo finito. Es decir, algo deviene otro, pero como lo otro también es algo, entonces éste deviene por consiguiente otro (y así hasta el infinito). Lo infinito se reduce a una mera negación de lo finito, dado que se parte de la afirmación de que lo finito es tan algo como su otro, por lo que el infinito progresa como el mero inter-cambio (una cosa en lugar de otra) de estas determinaciones que conducen (infinitamente) la una a la otra. La verdadera infinitud, nos dice Hegel, sucede cuando algo deviene otro y lo otro deviene lo otro de lo otro mismo. Y a diferencia del infinito malo, aquello a lo que se pasa es enteramente lo mismo que lo que pasa (ambos no tienen otra determinación que una sola y la misma, a saber, la de ser otro). Lo infinito no es contradicción, sino la vuelta a sí del devenir, el llegar a ser algo para sí. Solamente pasando a lo otro algo viene a coincidir consigo mismo y esta referencia a sí mismo en el pasar y en lo otro es la verdadera infinitud ${ }^{29}$.

27 Véase S. Žižek: «Hegel's Century», en: S. Žižek, C. Crockett y C. Davis (eds.): Hegel and the Infinite. Religión, Politics and Dialectic, op. cit., pp. IX-XII.

28 WdL. G.W., 11:37 (Trad., pág. 219): «Einheit des Unterschieden- und des Nichtunterschiedenseins- oder der Identität der Identität und Nichtidentität.»(la unidad del ser-diferenciado y del ser-no-diferenciado: o de la identidad y no-identidad).

29 Cf. Enz. § 95. G.W. 20: 131. (Trad., pág. 197). 
Ahora bien, hasta el momento hemos desarrollado las nociones de identidad y diferencia desde la lógica especulativa en Hegel. Resta, por tanto, el desarrollo de estas nociones desde la perspectiva de la filosofía de la diferencia, con objeto de ver en qué medida se distancian o no de la filosofía hegeliana. En este sentido, Deleuze y Derrida intentan de manera explícita rescatar de las redes «totalitarias» de Hegel la noción de diferencia (con todo, Derrida será más consciente de las dificultades de llevar a cabo la tarea). Deleuze expresa de un modo contundente su objetivo de partir de una diferencia pura cuando afirma, al comienzo de Diferencia y repetición, que «en el origen de este libro hay dos direcciones de investigación: la primera atañe a un concepto de la diferencia sin negación, precisamente porque la diferencia, no estando subordinada a lo idéntico, no llegaría o «no tendría por qué llegar» hasta la oposición y la contradicción» ${ }^{30}$. En suma, Deleuze identifica la diferencia en Hegel como «contradicción» y desde ahí elabora su crítica. Más aún, llega a decir que «Hegel determina la diferencia como la oposición de extremos o de contrarios» ${ }^{31}$, los cuales vienen a ser articulados por la diferencia entre Identidad (lo mismo) y la diferencia (lo otro). Y esta caracterización descansa en la noción de contradicción, con la que Deleuze describe la filosofía de Hegel: «Es preciso, además, que cada contrario expulse su otro, se expulse por consiguiente a sí mismo, y se convierta en el otro que expulsa. Tal es la contradicción, como movimiento de la exterioridad» ${ }^{32}$. Así, Deleuze cree hallar en Hegel un movimiento de expulsión y exterioridad, esto es, diferencia como negación de una cosa respecto a todo lo que ella no es. Al decir que una cosa es en su no relación con todo lo demás, Deleuze cree que la diferencia para Hegel no es diferencia, sino «mismidad». Es decir, un reforzamiento de la identidad por vía negativa. En resumidas cuentas, considera la diferencia hegeliana como «contradicción», «exterioridad» y «mismidad». A este respecto, lo primero que cabe señalar es que la noción de contradicción de la que habla Deleuze difiere de la noción de contradicción que emplea Hegel cuando define así la proposición lógica: «lo negativo es precisamente en la misma medida positivo», de modo «que lo que se contradice no se disuelve en cero, en la nada abstracta sino, esencialmente, en la sola negación de su contenido particular, o que una tal negación no es toda ella negación sino la negación de la Cosa determinada, que se disuelve, como lo que es negación determinada» ${ }^{33}$. En segundo lugar, tal y como hemos intentado demostrar en la sección anterior, la diferencia en Hegel no se reduce a una contradicción externa (cuantitativa). Y, menos aún, a mismidad. Deleuze combate a Hegel porque quiere demostrar que las cosas difieren respecto de sí mismas, es decir, demostrar que la diferencia no precisa excluir para afirmarse. Sin embargo, ¿no es justamente Hegel quien sostiene que la oposición externa de las cosas radica en una auto-oposición inmanente, que las cosas finitas difieren de las otras (igualmente finitas) porque justamente no son idénticas consigo mismas? Por otra parte, pareciera que la crítica que Deleuze realiza a Hegel no partiese ni de su concepción de la dialéctica, ni de su pensamiento especulativo, sino de la «dialéctica habitual» que el mismo Hegel no se cansó de combatir ${ }^{34}$.

Cuando Hegel piensa el vínculo entre «ser»y «nada», critica la actitud de la «dialéctica habitual» que parte de una oposición originaria entre los elementos, puesto que: «Cuando viene

30 G. Deleuze, Diferencia y repetición, Buenos Aires, Amorrortu, 2002, pág. 16.

31 Op. cit., pág. 84.

32 Op.cit., pág. 85.

33 WdL. G.W., 11: 25. (Trad., pág. 203).

34 Cf., WdL. G.W., 11: 25-26. (Trad., pp. 202-203).

Daimon. Revista Internacional de Filosofía, $\mathrm{n}^{\circ}$ 64, 2015 
presupuesta la absoluta escisión del ser respecto de la nada, el inicio o el devenir es entonces algo desde luego inconcebible (...) pues se hace una presuposición que suprime el inicio o el devenir». Hegel, en cambio, piensa la dialéctica a partir de la «unidad» de ser y nada, es decir, desde una concepción del ser como devenir, puesto que: «el devenir es una unidad tal de los mismos que se halla en la naturaleza de cada uno de ellos; el ser es en y para símismo la nada, y la nada es en y para sí misma el ser ${ }^{35}$. Para Hegel, no hay en primer lugar una dualidad primordial entre elementos, sino la grieta intrínseca del Uno sin nombre, pero manifiesta en y como devenir (werden). Por lo que aquí el antagonismo no supone una tensión armoniosa entre los dos principios o elementos opuestos, sino que implica la tensión interna, la imposibilidad de autocoincidencia del ser consigo en cuanto ser (o de la nada en cuanto nada, que para el caso da lo mismo). La dialéctica no es la expresión acabada de una contradicción entre elementos que, siendo cada uno idéntico a sí mismo, se opone al otro, sino un momento de lo lógico, en el que las determinaciones hacen la «experiencia de sus propios límites», dando lugar al pensamiento especulativo. Este tercer respecto de lo lógico no es sino el momento en el que se comprende «la unidad de las articulaciones contrapuestas». Así, la relación de oposición entre los elementos es impura, la oposición no es la relación de determinaciones opuestas en algo externo a ellas como su fundamento, «sino que el fundamento de la contraposición es el movimiento -no un «sustrato»- del recíproco asumirse una determinación en la otra» ${ }^{36}$. Por lo que hace al propio Deleuze, habría quizá que decir que, en el mejor de los casos, cuando cree combatir a Hegel en realidad no hace más que establecer vínculos subterráneos con él. Lo primero que cabe señalar es que Deleuze, al igual que Hegel, considera que la principal tarea de la filosofía es tratar con conceptos, un auto-movimiento del concepto. En esa línea, hay una serie de afinidades conceptuales entre Hegel y Deleuze que han sido resaltadas por Žižek en Órganos sin cuerpo. Tal es el caso del término hegeliano «universal concreto», término que el filósofo francés expropia a Hegel para elaborar, bajo la expresión «universalidad concreta», el modelo generativo de un proceso de devenir opuesto a los universales abstractos que sirven para categorizar modos de ser de la realidad establecida.

Cuando Deleuze critica la lógica platónica de los tipos ideales universales que designan la misma cualidad, se percibe una extraña proximidad con la crítica hegeliana a la universalidad abstracta. Otro vínculo subterráneo entre Deleuze y Hegel viene dado por el papel que cumple la inmanencia en cada uno de los filósofos. En el caso de Hegel, la inmanencia está a la base de su concepción del devenir, en el que la relación de inmanencia entre el para sí y el en sí es ella misma para nosotros: somos nosotros, en la inmanencia de nuestro pensamiento, quienes experimentamos la distinción entre la manera en que las cosas se nos aparecen y la manera en que son en sí mismas. La distinción entre realidad aparente y trascendente es de por sí un resultado del modo de apariencia de lo empírico; cuando decimos que una cosa es en sí, esto significa, en cierto modo, que se nos aparece en esta forma de ser. Mediante el concepto de plano de consistencia, Deleuze apunta en la dirección de la inmanencia absoluta, como univocidad del ser que reitera la noción de inmanencia en Hegel (aunque, claro está: Hegel nunca admitiría la univocidad del ser). Como dice Žižek, la mínima diferencia entre Hegel y Deleuze no descansa tanto entre inmanencia y trascendencia sino entre hiato

35 WdL. G.W., 11: 55. (Trad., pág. 237).

36 F. Duque, op. cit., pág. 434 (nota a pie nº 923). 
y flujo, puesto que el empirismo trascendental de Deleuze es la absoluta inmanencia del flujo permanente del puro devenir, mientras que el «hecho último» de Hegel es la irreparable ruptura de y en la inmanencia. La inmanencia no es un hecho inmediato, sino el resultado que se produce cuando la trascendencia es sacrificada y se retrotrae a la inmanencia. Por su parte Derrida, a diferencia de Deleuze, intuye de entrada que atacar «externamente» a Hegel significa otorgarle un triunfo anticipado, así que su acercamiento al maître-filósofo no consistirá en un enfrentamiento directo. Lejos de oponerse a la noción de diferencia elaborada por Hegel, «juega» a diferir de él, desde él mismo. Derrida incluso llega a admitir «las relaciones de afinidad muy profunda que la diferencia [différance] así escrita mantiene con el discurso hegeliano» ${ }^{37}$, de modo que no se trataría de romper abiertamente con él, cosa que no tendría «ningún tipo de sentido ni de oportunidad», sino de «operar en él una especie de desplazamiento a la vez ínfimo y radical» ${ }^{38}$. En su ensayo La différance, Derrida se sirve de una traducción que Alexandre Koyré hace de algunos de los pasajes de la Lógica de Jena para explorar la traducción de la expresión differente Beziehung. Además de advertir cierta extrañeza ante el empleo del término latino differente por parte de Hegel ${ }^{39}$, Derrida modifica la traducción de Koyré y sugiere la siguiente: rapport différenciant (relación diferenciante), la cual será clave en su pensamiento, en tanto presencia que se escinde de sí misma.

En este sentido, podría afirmarse que bajo el nombre de différance, Derrida se explica sobre Hegel: «Escribir differente o différancia [con una a] podría ya tener la utilidad de hacer posible, sin otra nota o precisión, la traducción de Hegel en este punto particular que también es un punto absolutamente decisivo de su discurso» ${ }^{40}$. El exceso enigmático e imposible de la différance constituye el fundamento y el origen de todo, pero no al modo de una presencia inmóvil sino, en términos de Hegel, al modo de un movimiento infinito que afirma lo absoluto en la escisión de sí mismo. En tanto que «diferenciante», la relación produce lo finito por la violencia irreductible de la inversión, de la diseminación y el flujo. La diferencia imprime a lo real la forma de una conexión múltiple, establecida en el desdoblamiento esencial de todas las cosas. La différance temporaliza, espacializa y, al mantener abierto el juego de la existencia, actúa como la huella que impide la clausura de la representación y el sentido. Es decir, la différance sostiene lo finito en la des-fundamentación de sí misma: «La diferencia [différance] es el «origen» no-pleno, no-simple, el origen estructurado y diferente (de diferir) de las diferencias. El nombre de «origen», pues, ya no le conviene» ${ }^{41}$. La différance es ese movimiento de «espacialización» $\mathrm{y}$ «temporalización» que separa «un intervalo de lo que no es él para que sea él mismo». Así, la diferencia en Derrida abre una grieta dentro del discurso de la identidad, al decir que: «Lo mismo es precisamente la di-ferencia [différance] como paso alejado y equivocado de un diferente a otro, de un término de oposición a otro.» ¿Pero esta grieta no había sido abierta ya por Hegel? Cuando Derrida dice que: «las parejas en oposición sobre las que se ha construido la filosofía y de las que vive nuestro discurso para ver ahí no borrarse la oposición, sino anunciarse una necesidad tal que uno de los términos aparezca como la di-ferencia [différance] del otro, como el otro diferido en la

37 J. Derrida, «La Différance», en: J. Derrida, Márgenes de la filosofía, Madrid, Cátedra, 1989, pág. 50.

38 Ibidem. Recordamos que la palabra Différance es un neografísmo de la palabra Différence.

39 A este respecto, Hegel suele emplear los términos alemanes verschieden o ungleich.

40 Op. cit., pp. 49-50.

41 Op. cit., pág. 47. 
economía del mismo ${ }^{42}$ parece expresar de otro modo el corazón del pensamiento hegeliano. Ahora bien, Derrida desdeña el movimiento de la dialéctica hegeliana ${ }^{43}$ porque considera que ésta configura una economía de la vida que «se restringe a la conservación, a la circulación y a la reproducción tanto de sí como del sentido». Desdeña el trabajo de lo negativo que «conserva y retiene lo que ha sido suprimido» ${ }^{44}$, porque cree que esta Aufhebung ${ }^{45}$ es un mecanismo de «reapropiación» ${ }^{46}$ de toda la negatividad, una «inversión», una «amortización» del gasto absoluto a través del cual Hegel cerraría los ojos ante el «abismo sin fondo del sin-sentido en el que se saca y se agota el fondo del sentido».47 Más aún, llegará a decir que la «sumisión a la evidencia del sentido, a la fuerza de ese imperativo: que haya sentido (...) es la esencia y el elemento de la filosofía, de la onto-lógica hegeliana ${ }^{48}$. A nuestro entender, en el fondo de la argumentación de Derrida ${ }^{49}$ se aprecia la sombra de Lévinas y su temprana condena de la Aufhebung hegeliana como una simple estrategia donde las formas de otredad son absorbidas por la violencia totalizadora de la lógica de la identidad, el sentido, la historia, la representación, etc. Como reconoce el propio Derrida: «En estos límites y desde este punto de vista al menos, el pensamiento de la di-ferencia [différance] implica toda la crítica de la ontología clásica emprendida por Lévinas» ${ }^{50}$. Si Lévinas estuviera en lo cierto, Hegel no habría hecho otra cosa que suprimir las diferencias para salvaguardar la supremacía de la mismidad. Sin embargo, como venimos insistiendo a lo largo de nuestro trabajo, la unión (si se permite la precisión alemana: la Ver-einigung) de la que da cuenta el pensamiento especulativo no es la unidad (en alemán: Einheit, una cualidad abstracta) que resulta de la supresión de las diferencias, sino la resultante de la simultánea diferenciación y conservación de la diferencia. Por esa razón, nos resulta problemático seguir a Derrida y su enjuiciamiento de la Aufhebung como sumisión a la «evidencia» del sentido y la representación, una empresa totalizadora que reduciría lo otro a lo mismo. El juego de Derrida exige exceder la dialéctica como renuncia absoluta del sentido, una «puesta en juego» que intenta «hacer aparecer lo serio del sentido como una abstracción inscrita en el juego». Con todo, cabe preguntarse, ¿no es este «abismo sin fondo del sin-sentido» una nueva forma de inversión sin riesgo? Por tanto, ¿no incurre Derrida en lo mismo que critica -como hemos visto, de forma un tanto problemática- en el pensamiento hegeliano?

42 Op. cit., pág. 53.

43 J. Derrida, «El pozo y la pirámide. Introducción a la semiología de Hegel», en: J. Derrida, Márgenes de la filosofía, op . cit., pág. 109.: «Pero esta salida fuera de sí es el camino obligado de una vuelta a sí. Se piensa bajo la autoridad y en la forma de la dialéctica, según el movimiento de lo verdadero, vigilada por los conceptos de Aufhebung y de negatividad.»

44 J. Derrida, «De la economía restringida a la economía general. Un hegelianismo sin reserva», en: J. Derrida, op . cit., pág. 350 .

45 Op. cit., pág. 351.: «Mediante ese recurso a la Aufhebung que la puesta en juego conserva, ésta se mantiene como dominadora del juego, lo limita, lo trabaja dándole forma y sentido».

46 Cf., op. cit., pág. 352.

47 Op. cit., pp. 352-353.

48 Op. cit., pág. 352.

49 Op.cit., pp. 352-353.: «La noción de Aufhebung (el concepto especulativo por excelencia, nos dice Hegel, aquel cuyo privilegio intraducible detenta el alemán) es risible en cuanto significa el atarearse de un discurso que se extenúa en reapropiarse toda negatividad, en elaborar la puesta en juego como inversión, en amortizar el gasto absoluto, en dar un sentido a la muerte (...) Ser impasible, como lo fue Hegel, a la comedia de la Aufhebung, es cegarse a la experiencia de lo sagrado, al sacrificio perdido de la presencia y del sentido.»

50 J. Derrida, op. cit., pág. 56. 
Lejos de rechazar el recorrido llevado a cabo por la filosofía de la diferencia, lo que hemos intentado hacer aquí es poner en evidencia la unilateralidad con la cual muchas veces se asume el propio legado filosófico, lo cual paraliza el pensamiento y reitera los problemas que cree haber superado. La elección que llevamos a cabo ha sido clave, por eso, frente a la actitud de quienes desean reconciliar su propia época con el pensamiento, se vuelve necesario un el salto del tigre al pasado (en este caso, Hegel) que abra (otra vez) una brecha en nuestro presente y ponga en entredicho toda voluntad de cierre. No se trata tanto de contraponer la lógica especulativa al pensamiento de la diferencia, como de incorporar una «y»-que une y diferencia- ambas tradiciones. Probablemente, la cuestión radique en tomar en consideración algunas de las limitaciones del pensamiento histórico-crítico contemporáneo y preguntarse si en el fondo no reitera la negación abstracta propia del entendimiento, que ve oposiciones y contradicciones por todas partes, pero pretende reducirlas privilegiando uno de los extremos aisladamente tomado. De ahí la conveniencia de pensar nuevamente la concepción especulativa que está en la base del pensamiento hegeliano. En caso contrario, nos parece, seguiremos oscilando entre los tecnicismos de una filosofía profesionalizada que fracciona las ideas en apartados estancos, y la unilateralidad de una filosofía crítica que se refugia en sí misma para negar abstractamente aquello que la constituye, y que a ella misma la está amenazando desde dentro.

\section{Bibliografía}

Deleuze, G.: Diferencia y repetición, Buenos Aires, Amorrortu, 2002.

Deleuze, G. y Guattari, F.: Qué es la filosofía, Barcelona, Anagrama, 1993.

Derrida, J.: Positions, Minuit, Paris 1972.

- : Márgenes de la filosofía, Madrid, Cátedra, 1989.

Duque, F.: Historia de la filosofía moderna. La era de la crítica, Madrid, Akal, 1998.

Hegel, G. W. F.: Enzyclopädie der philosophischen Wissenschaften im Grundrisse (1830) (= Enz.) en: W. Bonsiepen und H-C. Lucas (eds.), Gesammelte Werke, Band 20, Felix Meiner, Hamburg, 1992, 379. (Trad. esp.: R. Valls Plana. Madrid, Alianza 1997).

- : Phänomenologie des Geistes (= Phä), en: W. Bonsiepen und R. Heede (eds.), Gesammelte Werke, Band 9, Felix Meiner Verlag, Hamburg, 1980. (Trad. esp.: A. Roces, México, FCE, 2007).

- : Wissenschaft der Logik (= WdL). Erster Band. Die objektive Logik, en: F. Hogemann und W. Jaeschke (eds.), Gesammelte Werke, Band 11, Felix Meiner, Hamburg, 1978. (Trad. esp.: F. Duque, Madrid, Abada, 2011).

Hyppolite, J.: Logique et existence. Essai sur la logique de Hegel, Paris, Presses Universitaires de France, 1953.

- : Introduction à la philosophie de l'histoire de Hegel, París, Seuil, 1983.

Lévinas, E.: Totalidad e infinito. Salamanca, Sígueme, 1977.

Nohl, H. (ed.): Hegels theologische JugendSchriften (Tübingen, 1907) (= Nohl), Frankfut/ Main, Minerva GmbH, 1966.

- : Escritos de Juventud (=EJ), Madrid, FCE, 2003.

Žižek, S.: Órganos sin cuerpo. Sobre Deleuze y consecuencias, Valencia, Pre-textos, 2006.

Žižek, S., Crockett, C. y Davis, C. (eds.): Hegel and the Infinite. Religión, Politics and Dialectic, New York, Columbia University Press, 2011. 